\author{
Military Technical College \\ Kobry El-Kobbah, \\ Cairo, Egypt.
}

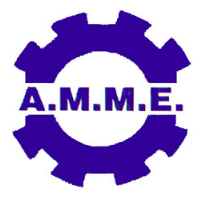

\title{
NONLINEAR FINITE ELEMENT MODELING OF CRYSTALLINE MICROSTRUCTURAL PROPERTIES WITH APPLICATION TO ALUMINUM ALLOYS FOR MODERN ARMORS
}

K. ElKhodary ${ }^{1}$ and M. Bakr ${ }^{1}$

\begin{abstract}
Often, large plastic deformation in polycrystals is influenced by the slip and its gradients, which arise at the length scales of microstructural heterogeneities, and in particular grain boundaries. In this work a non-local multiple-slip crystal plasticity formulation, i.e. augmented with gradients, is presented and applied to polycrystalline aluminum aggregates. Physically based dislocation-density mechanisms representative of different slip interactions coupled to plastic curvature have been formulated within the gradient-crystal plasticity framework. Specialized finite element methodologies that account for higher-order deformation are also presented and used to investigate how certain dislocation-density activities at grain boundaries are directly related to shear strain localization for polycrystalline aggregates which lead to damage tolerant armor alloys.
\end{abstract}

1 Department of Mechanical Engineering, American University in Cairo, Egypt. 